Soledad Díaz 1

Ellen Hardy 2,3

Gloria Alvarado 4

Enrique Ezcurra 5

\section{Acceptability of emergency contraception in Brazil, Chile, and Mexico. 2 - Facilitating factors versus obstacles}

\author{
Aceitabilidade da anticoncepção \\ de emergência no Brasil, Chile e México. \\ 2 - Fatores que poderiam facilitar \\ ou dificultar sua introdução
}

${ }^{1}$ Instituto Chileno de Medicina Reproductiva. Casilla 96, Correo 22, Santiago, Chile. 2 Universidade Estadual de Campinas.

C. P. 6181, Campinas, SP 13084-971, Brasil.

hardy@unicamp.br

3 Centro de Pesquisas Materno-Infantis

de Campinas.

C. P. 6181, Campinas, SP 13084-971, Brasil.

4 Instituto de Investigación Científica, Universidad Juárez. Apartado Postal 385, Oficina Central de Correos, Durango, Durango, México. 5 UNDP/UNFPA/WHO/World Bank Special Programme of Research, Development and Research Training in Human Reproduction. World Health Organization, CH1211 Geneva 27, Switzerland.

\begin{abstract}
A multi-center study was performed in Brazil, Chile, and Mexico to identify factors that may facilitate or hinder the introduction of emergency contraception (EC) as well as perceptions concerning emergency contraceptive pills. Background information on the socio-cultural, political, and legal context and the characteristics of reproductive health services was collected. The opinions of potential users and providers were obtained through discussion groups, and those of authorities and policymakers through semi-structured intervi ews. Barriers to introduction included: perception of EC as an abortifacient, opposition by the Catholic Church, limited recognition of sexual and reproductive rights, limited sex education, and insensitivity to gender issues. Facilitating factors were: perception of EC as a method that would prevent abortion and pregnancy among adolescents and rape victims; interest in the method shown by potential users as well as by some providers and authorities. It appears possible to reduce barriers through support from segments of soci ety committed to improving sexual and reproductive heal th and adequate training of heal th care providers.
\end{abstract}

Key words Contraception; Reproductive Health; Reproductive Health Services

Resumo Foram identificados fatores que poderiam facilitar ou dificultar a introdução da anticoncepção de emergência (AE) no Brasil, Chile e M éxico. Foram levantadas informações sobre o contexto sócio-cultural, político e legal bem como sobre as características dos serviços da saúde reprodutiva. As opini ões de potenci ai s usuários e possíveis provedores foram obtidas por meio de grupos de discussão, e as das autori dades e outras pessoas influentes por intermédio de entrevistas semi-estruturadas. Os obstácul os incluíram: percep ção da AE como abortiva; oposi ção da I greja Católica; pouco reconhecimento dos di reitos sexuais e reprodutivos; pouca educação sexual; efalta de sensi bili dade frente às questões de gênero. Os facilitadores foram: percepção da AE como um método que poderia prevenir o aborto e a gravidez entre adol escentes e víti mas de estupro; interesse no método mostrado por potenciais usuárias, bem como por al guns provedores e autoridades. Parece possível reduzir as barrei ras identificadas com o apoio dos segmentos da soci edade comprometi dos com a mel hora da saúde sexual e reprodutiva, e com o trei namento adequado dos provedores de saúde.

Palavras-chave Anticoncepção; Saúde Reprodutiva; Serviço de Saúde Reprodutiva 


\section{Introduction}

Unsafe abortion is still one of the main causes of maternal mortality in most of the developing world (Mundigo \& Indriso, 1999). An estimated $13 \%$ of the approximately 585,000 maternal deaths per year worldwide result from unsafe abortion (WHO, 1997). In almost all Latin American countries abortion is still illegal under all circumstances. Consequently the vast majority of abortions are unsafe. From 1986 to 1992 there were an estimated 38.1 abortions/ 1,000 women in Brazil, 45.4 in Chile, and 23.3 in Mexico (Singh \& Wulf, 1994). According to the Alan Guttmacher Institute (1994), in Brazil, Chile, and Mexico respectively, $18 \%$, $24 \%$, and $26 \%$ of women with induced abortions are hospitalized for complications. Many of these unwanted pregnancies occur during adolescence; fertility rates in Latin America range from 6.4 to 132 per 1,000 women in the 15-19-year group (OPS/OMS, 1995). Although emergency contraception (EC) is perceived as one means to reduce unwanted pregnancies (Consortium for Emergency Contraception, 1996; WHO, 1998), it is not provided by most of the region's family planning programs. When used, it is generally restricted to cases of rape.

A study was conducted to assess the acceptability of EC in Latin America and to obtain information to help design appropriate introductory strategies. The study involved Brazil, Chile, and Mexico, which represent different sociocultural and political contexts. This paper describes factors that could either facilitate or hinder the introduction of EC in these three countries. Other results are reported separately (Díaz et al., 2003).

\section{Methods}

A multidisciplinary team consisting of social scientists and biomedical researchers conducted the study, as reported (Díaz et al., 2003). During the preparatory phase, background information was collected on the socio-cultural, political, and religious context, reproductive and sexual health and rights, status of reproductive health services, and legal aspects relevant to EC introduction. The literature review was used to design the data collection instruments and identify obstacles and facilitators for the introduction of EC in each country. During the main study phase, participants' opinions were collected through qualitative methods (Kreuger, 1995; Taylor \& Bogdan, 1992).
Participants were selected from the following categories and sub-categories:

(a) Potential users: Adolescents, adolescent mothers, adult childbearing-age women, and mothers of adolescents. All potential users were lower or lower-middle class.

(b) Potential providers: Health workers, schoolteachers, and counselors and women's health activists. All served in the public sector or in NGOs working in poor areas.

(c) Authorities and influential persons: Health, educational, and judiciary policymakers and administrative authorities as well as opinionmakers who may participate in or influence the decision-making process related to the introduction of EC programs and services. Individuals who may participate in or influence the decision-making process related to the introduction of EC in the community. These included authorities (policymakers and managers from the health, educational, and judiciary areas and youth programs), leaders of professional associations (obstetricians/ gynecologists, midwives, nurses) and NGOs concerned with reproductive health, as well as other influential persons.

Potential users and providers were identified through the snowball or chain-sampling technique (Patton, 1990). Authorities and influential persons were selected based on their roles in national or local governments, professional associations, or NGOs.

\section{Data collection}

Opinions of potential users and providers were collected through three consecutive group sessions (discussion groups), held a week apart. The same five to twelve subjects from each subcategory of participants (and with similar socioeconomic status) took part in the three sessions. Opinions on each of the target topics were prompted by direct questions, followed by free discussions on issues relevant to each particular group. The opinions of authorities and influential persons (as well as some providers in Brazil) were obtained through semi-structured (individual or collective) interviews. Written materials describing EC methods were provided in advance to all interviewees.

A total of 35 discussion groups (Brazil =7; Chile $=14$; Mexico $=14$ ) and 78 interviews (Brazil =44; Chile =19; Mexico =15) were conducted and analyzed. Group discussions and interviews were tape-recorded. Handwritten notes were taken as a back-up for discussion groups. Transcriptions of the recordings were read and coded according to five thematic ar- 
eas: local context; previous knowledge of EC; perceptions of EC; facilitating factors and obstacles for the introduction of EC; and strategies (means) suggested for its introduction. The Ethnograph v4.0 software was used to code the transcriptions and identify theme codes. Analysis and interpretation of the results presented here consisted of the identification of strategies suggested by participants for the introduction of EC, including facilitating factors and obstacles, as well as means for introduction of the method.

The project was approved by the appropriate Institutional Review Boards (IRB) in each country and then by the Scientific Committee for Research Involving Human Subjects under the World Health Organization (WHO). Signed informed consent was obtained from all participants.

\section{Results}

\section{Obstacles}

Similar obstacles were detected in the three countries, although the weight attributed to them differed. In general, fewer barriers were perceived in Brazil and more in Chile, with M exico in an intermediate situation. Barriers identified or perceived by the participants were:

(a) Socio-cultural: In Chile and Mexico, participants anticipated strong opposition to EC from the Catholic Church and the political right, considering the method an abortifacient and a method encouraging irresponsible sexual behavior among adolescents. This was a lesser concern in Brazil.

In Chile, all participants mentioned the current conservative public opinion regarding sexual and reproductive health. Many referred to limited recognition of sexual and reproductive rights. Some participants thought that even the left-wing political parties have conservative attitudes towards these issues.

"Conservative attitudes are the main barrier to EC as a state policy in this country." (Parliamentarian, Chile)

"In the area where we work, the Catholic Church will oppose it; we know it is very strong, very dominant. The Church won't allow it." (Midwife, Chile)

"Catholics will percei ve such an emergency method as perverse and demoniacal." (Youth program officer, Chile)

In Mexico, where an effort has been made to introduce EC, the reaction by conservative sectors represented by the Catholic Church and the Pro-Life movement was extremely negative. These groups are actively engaged in blocking the introduction of EC, to the point of taking legal action.

"My opinion on this method is that of the Church, and it must not be used because it may even be a micro-abortive method." (Priest, Mexico)

In Brazil, participants anticipated that some sectors of society could resist the introduction of EC. However, participants from all categories felt that this would not prevent wide dissemination and use of the method and that there would be little resistance from society as a whole. They felt that barriers to EC would be more related to individual perspectives than to social or political factors.

“...l believe that only lack of information [would be a barrier], but once [the woman] knows [about EC], I expect there will no resistance... religion, those things, I don't think [they will bea problem]." (Adult woman, Brazil)

"[EC] has been in the protocols for two years, so legally there's no problem." (Physician, influential person, Brazil)

In the three countries, adolescent pregnancy is a major personal and public health problem, but there has been little or no open discussion on the subject. Government strategies to solve the problem have been ineffective. There is little knowledge about reproductive matters among adolescents and adults. Sex education in schools (particularly public schools) is rare. In Chile, timid attempts to introduce sex education prompted strong opposition from conservative opinion-makers and a national debate that jeopardized the initiative.

Participants, particularly adult women and health activists, identified gender factors affecting women's free decisions regarding sexual and reproductive life as barriers to EC. Chauvinism and partner's pressure to have children (in Chile and Mexico) may interfere with decisions by women, especially those with less autonomy.

(b) Legal and programmatic: EC does not appear in the Chilean or Mexican legislation or national family planning guidelines. Legal aspects were perceived as a significant obstacle in Chile, where abortion is illegal and penalized under all circumstances (including rape and risk to the woman's life) because of the perception that EC causes a "micro-abortion".

In Chile, public sector health providers are not authorized to offer contraceptive services to unmarried adolescents. However, EC was mentioned in the 1998 Ministry of Health guidelines for care of adolescent victims of sexual vi- 
olence, calling for prevention of pregnancy after rape by using post-coital contraception. No drugs or doses were mentioned. However, this recommendation was excluded through an erratum requesting that the reference to pregnancy prevention be ignored.

(c) Health services: Participants from all categories in the three countries thought that the time frame for EC poses a problem. Accessibility to family planning is limited, in part because providers are overburdened and in part due to bureaucracy at health centers. Health workers and managers do not consider provision of contraceptives as an emergency service. In addition, providers reported that in the case of unprotected intercourse, users either do not resort to public clinics or go there too late.

"If one complies with all the bureaucratic procedures for these emergency contraception cases, it cannot happen... the emergency [time frame] will have expired." (Midwife, Chile)

"Often the protocol reaches the health service, but only the director's desk, and remains in a drawer. The attending physi cian in the health post never sees the protocol. Meeting the protocol criteria makes EC use easier, but does not necessarily guarantee that patients will have access to it. Women go to the health center, and the earliest appointment they get is the following week. EC has to be used within a maximum of 72 hours, so they don't have access to it in real-life situations" (Instructor of health professionals, Brazil).

In all three countries, although family planning services were available, clients were mainly adult women. Low-income adolescents and women have less access to health care than the general population. Many public sector clinics offer poor quality of care, with inadequate infrastructure and lack of privacy, which can intimidate women from discussing the need for EC. This factor was particularly relevant for adolescents who participated in the study. Health services have scarce financial and human resources allocated to family planning and are short of contraceptive supplies. Some providers feared that the introduction of EC would cause an abrupt raise in the demand for contraceptive methods, which they might not be able to meet.

"At a given moment this may create a social and medical problem. The demand for this method may surpass the availability of services" (Health authority, M exico).

Services for victims of sexual violence were not available in all clinics. Existing services prioritized legal procedures, medical trauma, and psychological support. Less attention was paid to the prevention of pregnancy and STDs, although in Brazil and Mexico EC was offered to rape victims by the health workers interviewed. (d) Public sector providers (health and education): In Chile and in Mexico, and to some extent in Brazil, health workers were unfamiliar with EC or had incomplete information about it. Many health care providers and authorities from the three countries commented that clinical staff lacked the appropriate training (technical and quality-of-care) to offer EC counseling or services.

"We have doubts about the doses, dosing schedule, and side effects" (Health service provider, Mexico).

“Most physicians are unfamiliar with EC. One of the greatest difficulties we face is for physicians in the service (seeing patients) to learn what exists in the protocol. It is difficult to disseminate information, and we are working to create mechanisms" (Gynecologist, health authority, Brazil).

Health care providers from the three countries may also be reluctant to offer information on EC out of fear that it will promote irresponsible sexual behavior among adolescents or that it may be used inadequately, e.g., as a routine contraceptive method. In Chile, health care providers were particularly concerned over the fact that EC is not included in Ministry of Health guidelines and feared legal problems and moral sanctions if they prescribed it, especially for young girls. Some teachers, particularly in Chile, showed cultural and religious barriers to informing about EC or making it available to adolescents. Conservative attitudes and lack of sensitivity towards women's needs were also mentioned as obstacles that some health care providers and teachers experience.

“We (midwives) have to be extremely careful because we take risks doing things that we are not authorized to do by the protocol" (Midwife, Chile).

(f) Commercial: There were no registered products for EC in either Chile or M exico, which hinders both the introduction and correct use of EC. Pharmaceutical companies in the two countries were not interested in producing a specific EC formulation. In Chile, pharmacy chains refused to inform about EC or sell contraceptive pills as EC unless the government explicitly authorized them.

"The different pharmaceutical chains take similar approaches; nonewill distributea product like EC if it is not approved by the Ministry of Health. Even if approved, there would be no display or advertising" (Manager of a pharmacy chain, Chile). 
(g) Mass media: In both Mexico and Chile, participants doubted the media's interest in promoting EC. In Chile, the most conservative groups own or dominate the mass media. This leads to self-censorship, which precludes any exchange of information on sexual matters and the inclusion of more progressive opinions.

(h) Potential users: An important barrier detected by potential users was their lack of knowledge about reproductive biology and contraception. Limited sex education prevents women from identifying their fertile period, so they have little awareness of when they are at risk of becoming pregnant. Many potential users did not consider themselves at risk of unwanted pregnancy and they tended to mention other social or age groups as at risk. Women may thus receive information about EC but consider it irrelevant to them. As a consequence, they may not have it at hand when needed. Lack of knowledge may also contribute to the dissemination of distorted information about EC.

Some participants, particularly potential users from the three countries, expressed concerns or fear of acute or long-term side effects of EC, also perceived as a potential barrier to the use of pills. The short time for the EC decision and the need to access a health service within the required 72 hours were other worrisome aspects for potential users. The risk of subsequent guilt feelings was also perceived as a barrier for potential users in Chile and M exi$\mathrm{co}$, but was not mentioned in Brazil.

Additional obstacles to EC were mentioned as applicable to lower-income women. The women's relative isolation may preclude timely access to the relevant information. Potential users in the three countries mentioned their previous negative experiences at public health clinics, which may prevent them from requesting EC or insisting on their right to it. Lower-income women may not be able to afford pills at pharmacies. Negative popular beliefs about contraceptive methods in general or negative experiences while using pills were also perceived as obstacles. Women's health activists reported that particularly among poor women, the social meaning of motherhood is viewed as women's identity and destiny; this could be another barrier, since these women may not feel the need for EC.

Adolescents felt that they would face some specific obstacles, like few or no special health services for them and lack of information about contraceptives. Many adolescents reported difficulties communicating about sexuality, both with parents and adults in general. They also mentioned the obstacles to contraceptive use raised by parents, who do not want their children to become sexually active. Therefore, adolescents fear the reactions of adults (parents and potential providers) to their sexual activity or their request for EC. Some health care providers and teachers also fear parents' reaction if information about EC is provided:

“Parents say, 'I'm going to give my daughter moral norms, which she'll have to use to protect herself'. And one cannot interfere and disrupt the family system" (Teacher, Chile).

"When 14-year-old girls come for contraception, it's difficult for us. If the parents find out and complain, we're unprotected" (Midwife, Chile).

"I took my daughter to the health service and the midwife asked why she wanted something if she was so young" (Community health worker, Chile).

“One teacher expelled a student because he stood up in the middle of class and asked, 'What's an orgasm?' And the teacher, instead of explaining, said, 'Leave the room immediately!'” (Teacher, M exico).

Several other factors may contribute to the absence of timely actions among adolescents: low awareness of the risk of pregnancy; magical reasoning ("this is not going to happen to me"); and lack of care for self or experience with other contraceptive methods. New emotional feelings at the time of sexual initiation may attract girls' attention more than the fear of pregnancy.

According to the interviews, adults experience difficulty informing adolescents about $E C$, since many parents fail to discuss sex with their children. They also oppose others giving them information about contraception. Most adolescents learn about sex and contraception from their peers. The accuracy of such information is limited and may affect the quality of what they learn about EC.

$\underline{\text { Facilitating factors }}$

Some of the factors that may facilitate the introduction of EC were similar in the three countries, but important differences were also identified.

(a) Socio-cultural: According to influential persons, the Brazilian social context is favorable to dissemination of information and provision of EC by health services. In the three countries, most participants considered EC necessary because of the increase in teenage pregnancies and the need to prevent pregnancy resulting from rape, user-related contraceptive failures, or contraceptive accidents. From both the in- 
dividual and public health perspectives, EC was clearly considered a useful means to prevent unwanted pregnancies.

Some participants considered EC part of the reproductive and sexual rights agenda that they are promoting. In the conservative Chilean environment, EC was considered the "lesser of two evils" as compared to abortion, and this argument was felt to foster its acceptability.

In the three countries, participants, particularly potential providers and authorities, thought that introduction of EC would be easier if information about the method were included in an extensive educational project on sexuality and contraception. Both Brazil and Mexico have included sex education in school programs, although the implementation is limited.

"It is important that our children have information about sex and how to prevent diseases and pregnancy" (M other of adolescents, Mexico).

"We must not recommend EC as a contraceptive method ... we must not disseminate information that, if sexual intercourse occurs, so many pills should betaken, and the girl won't get pregnant. That is not the most appropriate orientation. It is more appropriate to say that family planning can be practiced with several methods and that EC is reserved for special situations" (Gynecologist, Brazil).

(b) Legal and programmatic: In Brazil, EC is supported by the Family Planning Act of 1996, the national family planning guidelines, and the health care protocol for rape victims (MS, 1996). Providers and influential persons agreed that this was the main facilitating factor because it provides legal and technical recourse for health workers and makes the method more acceptable to them. Nevertheless, interviewees reported that the protocol itself does not guarantee access to EC and that mechanisms to guarantee its actual application are needed.

In Mexico, EC has not been included in the official guidelines on care for rape victims. Health authorities expressed interest in making this method available and anticipated that it would soon be included in the national family planning guidelines.

In Chile, new policies on sexual violence allow physicians in health centers to act as forensic medical experts. This could prove to be a positive element if the decision to provide EC is also left to these health professionals. Participants felt that EC in the case of rape would be more acceptable to conservative groups. However, they felt that the official inclusion of EC in the protocol would facilitate its introduction:
"This topic [sexual violence] is covered by the media. We are the ones invited to TV programs, not those responsi ble for pregnancy prevention among adolescents. We can use this opportunity, but weshould not anticipategreat institutional changes. Progress will comethrough the good will of people working within such institutions" (Health provider for rape victims, Chile).

"If some document from the Ministry says that EC can be used, that would provide the backing to implement a program" (Local health authority, Chile).

(c) Health services: In all three countries, family planning services are widely available, free or at low cost. Contraceptive pills that can be used for EC are provided in public clinics. In some settings, EC could be part of emergency services. Providers and authorities agreed that EC should be available in health clinics.

Brazilian providers also emphasized that all municipal health posts in the Center and South of the country have gynecologists who may be willing to provide EC. In Chile, local and municipal family planning services can dictate special guidelines and determine specific functions for their health professionals, according to local needs. This could favor the introduction and use of EC in places where more liberal authorities are in charge.

"I believethe conditions exist: wehavehealth centers scattered around the city, and there are doctors and nurses" (Gynecologist, health authority, Brazil).

Providers from the three countries emphasized the need to present EC as one amongst other contraceptive options, within the educational activities of the family planning clinics, rather than as a separate activity. The availability of appropriate educational materials will facilitate dissemination of information. The means to convey the information are available at the service level.

(d) Public sector providers (health and education): In the three countries, professionals committed to improving sexual and reproductive health (midwives, schoolteachers, psychologists, social workers, and community health workers) were interested in collaborating in the introduction of EC. In Chile, some progressive local authorities and health care providers expressed interest in including the method as an option in their clinics, disregarding the fact that it is not included in the national family planning guidelines.

"You may be afraid, but you take this path and nobody can stop you. It is gratifying. We have started things on a small scale and been 
successful. Therefore, EC is another alternative to offer, a means to improvecare" (Midwife, Chile).

Other attitudes viewed as facilitating factors were providers' acceptance of the need for contraception, their awareness of the problems resulting from unwanted pregnancies, and their interest in helping their clients. Although not all providers have these positive attitudes, it was felt that many would share the interest in offering EC for the reasons mentioned.

(e) Commercial: In Brazil, when the data were collected it was expected that a specific EC product would soon be available on the market. This in fact happened in 1999. Although there is no registered EC product in Chile or Mexico, oral contraceptives are sold over the counter in both countries. The method is thus available to women who have the information on how and when to use it.

(f) Mass media: In Brazil and Mexico, it was felt that the media would collaborate in the dissemination of information about EC, i.e., introduction would be easier if the media were used carefully and the difference between EC and RU 486 (when used as an abortifacient) were made clear. Interviewees in Chile referred to the possibility of disseminating information through some women's magazines and radio and TV programs in which the journalists are reportedly more open to discussing sexual and reproductive issues. In addition, Chilean participants ascribed great importance to alternative information channels and reported that the information provided in the discussion groups had already circulated through NGOs and informal women's networks.

(g) Potential users: The majority of potential users from the three countries expressed great interest in the method. Many young women expressed the desire to care for their own health and prevent unwanted pregnancies and abortions. Therefore, they would use EC in a responsible way if they had the information beforehand and a health service nearby. Some mothers of adolescents agreed to provide information about EC both to their sons and daughters and to their friends.

"We should consider this [EC] before our children make a mess of their lives and spoil them 'for the rest of the trip'" (Mother of adolescents, Chile).

Adult women have experience with contraceptives, and would thus have little difficulty handling EC. As opposed to condoms, EC does not require negotiation with the sex partner, and women can avoid intervention by partners, relatives, or providers. Although family life and motherhood are highly valued in the cultural context of all three countries, women receive little support from either their partners or the state in the tasks and duties associated with their role. This is a strong motivation to use contraception in general and would also facilitate the acceptance of EC as the need arises.

In Chile, sexual practices differ from the officially stated conservative values, and participants perceived that potential users would easily recognize the value of EC if they received appropriate information.

"Families are willing to accept the different shades of reality, they are not rigid about principles, and they make concessions to support their children" (Educational authority, Chile).

Brazilian participants felt that personal decisions regarding $\mathrm{EC}$ would be based on individual needs and values rather than external norms and that the conservative attitude of the Catholic Church would not be a barrier in this country.

"I believe that (the subject of moral and religi ous values) is no longer (an obstaclefor implementing EC). It is very difficult to find people nowadays who consult a priest before making a decision" (Instructor of health professionals, Brazil).

(h) Collaboration among institutions: In the three countries, several organizations are actively involved in the introduction of EC by training personnel, disseminating scientific information, implementing field activities, and conducting biomedical research.

\section{Discussion}

The socio-cultural and political aspects that may influence the acceptability of EC showed similarities and differences between Chile, Brazil, and Mexico. There was limited recognition of sexual and reproductive rights, with conservative attitudes towards sexuality in the three countries. However, the power of the Catholic Church and conservative political sectors is greater in Chile and M exico than Brazil; meanwhile, the progressive sector is stronger in Brazil and weaker in Chile.

The main barrier anticipated by interviewees is the potential perception of EC as a means to induce early abortion. In Brazil, this concept may imply conscientious objection by some women in need of the method. It apparently carries greater weight in Mexico and Chile, where abortion is more heavily penalized both socially and legally. Chile represents the extreme situation, since abortion is penalized under all circumstances and some power- 
ful political sectors perceive any post-coital intervention as potential abortion. Exclusion of EC from protocols for the care of rape victims is an example of the political power of conservative sectors in Chile.

Another significant barrier, mainly in Mexico and Chile, is the conservative attitude of society towards sexuality. This precludes an open discussion of reproductive and sexual health problems and is particularly important for adolescents, who receive limited sex education and have little or no access to contraception. In the Latin American culture in general, parents prefer to believe that their daughters are not engaged in sexual activity, and communication about this matter between adolescents and adults is difficult.

This study identified significant barriers to the introduction of EC at the health program and services level. Commitment by political and administrative authorities is required to overcome such barriers. Ministry of Health family planning guidelines in Mexico and Chile and protocols to treat cases of sexual violence in Chile need to be revised to include EC. Although Mexican authorities have expressed their willingness to include the method in the program, this goal was not achieved within the time frame of the present study. Access to family planning services should increase, particularly for low-income adolescents and women. Services to treat victims of sexual violence should be widely available and include prevention of pregnancy following rape. Efforts to introduce products for EC in Chile and Mexico are also needed to facilitate use in the absence of accessible clinical services.

In the three countries, gender imbalance affects women's free decisions concerning both their sexual and reproductive life and contraceptive practices among adolescents and adult women. However, Brazil has a stronger and more vocal feminist movement which has contributed to some extent to protecting reproductive and sexual rights at the political level, a trend that has still not occurred in either Chile or Mexico.

One important facilitating factor for the introduction of EC, perceived as such by most participants in this study, is that EC could be a useful means to prevent sexual and reproductive health problems in the region. Adolescent pregnancy rates are high, and unwanted pregnancies are occurring in large numbers, resulting in high abortion rates, most of which are unsafe. Participants felt that public opinion, informed about these facts, would agree to the introduction of EC.
Another facilitating factor is that public sector clinics are spread nationwide in the three countries and provide free or low-cost contraceptives. In Brazil, despite difficulties in accessing family planning services, more frequent use has been observed (BEM FAM / M acro International, 1997). Likewise, despite limited access to such facilities, demographic indicators show that family planning programs have helped reduce fertility rates, particularly in Chile and Mexico. These clinics can play a major role in the introduction of EC if the method is included in family planning guidelines, as in Brazil.

EC has elicited great interest among potential users, women's health activists, and providers. Such interest should be a powerful component of any introductory strategy, collaborating with the dissemination of information. The method's use requires community awareness of its existence, so that informed women who need EC can claim their right to it from the public sector or purchase pills over the counter.

Commitment by government authorities in Brazil and Mexico is another highly significant component of a successful introductory program. Unfortunately, only some progressive local authorities in Chile are actually interested in making EC available, and the political environment in this country appears to be a significant obstacle.

Most participants had opinions about obstacles and facilitating factors for the introduction of EC that agreed with those identified by the researchers while reviewing the background information. There are important facilitating factors already in place. With different degrees of difficulty, we believe that the barriers can be overcome. Training of providers within the official health sector and individuals working at the community level is essential for the success of this process. Support by government authorities in Brazil and Mexico and important sectors dealing with sexual and reproductive rights in Chile is needed to achieve this goal. 


\section{Acknowledgments}

We are grateful to all participants for sharing their perceptions and thoughts and to the Andrew W. MelIon Foundation for providing major financial support to this project. The study was also supported by the UNDP/UNFPA/WHO/World Bank Special Program of Research, Development, and Research Training in Human Reproduction and by the home institutions of the respective research teams. The authors also acknowledge the collaboration of: Maria José D. Osis; Graciana A. Duarte, Magaly Possan; Ximena Espejo; and Ana Luisa Jiménez (Brazil); Soledad Sánchez; Paulina Vidal; Gloria Salazar; Paola Díaz; and Verónica Schiappacasse (Chile); Gerardo Cosain; Cecilia Navia; Alberto Terrones; M aria Silvia Aldaba; Sergio Estrada; and Jesús Arreola (M exico).

\section{References}

ALAN GUTTMACHER INSTITUTE, 1994. Aborto Clandestino: Uma Realidade Latino-Americana. Nova York: Alan Guttmacher Institute.

BEMFAM (Sociedade Civil Bem-Estar no Brasil)/ M ACRO INTERNATIONAL, 1997. Pesquisa Nacional sobre Demografia e Saúde, 1996. Rio de Janeiro: BEMFAM/Claverton: Macro International.

CONSORTIUM FOR EMERGENCY CONTRACEPTION, 1996. Emergency Contraceptive Pills. A Resource Packet for Health Care Providers and Program Managers. Washington, DC: Consortium for Emergency Contraception.

DIAZ, S.; HARDY, E.; ALVARADO, G. \& EZCURRA, E., 2003. Acceptability of emergency contraception in Brazil, Chile, and Mexico. 1 - Perceptions of emergency oral contraceptives. Cadernos de SaúdePública, 19:1507-1517.

KREUGER, R. A., 1995. Focus Groups: A Practical Guide for Applied Research. 2nd Ed. Newbury Park: Sage Publications.

MS (Ministério da Saúde), 1996. Anticoncepção de emergência. In: Assistência ao Planejamento Familiar (Serviço de Assistência à Saúde da Mulher, org.), pp. 121-125, Brasília: Coordenação de Saúde da Mulher, MS.

MUNDIGO, A. I. \& INDRISO, C. (ed.), 1999. Abortion in the Developing World. New Delhi: World Health Organization/Vistaar Publications.
OPS (Organización Panamericana de la Salud)/ OMS (Organización Mundial de la Salud), 1995. Indicadores Básicos. Situación de Salud en las Américas. Washington, DC: OPS/OMS.

PATTON, M. Q., 1990. Qualitative Evaluation and Research Methods. 2nd Ed. Newbury Park: Sage Publications.

SINGH, S. \& WULF, D., 1994. Estimated levels of induced abortion in six Latin American countries. International Family Planning Perspectives, 20:413.

TAYLOR, S. J. \& BOGDAN, R., 1992. Introduction to Qualitative Research Methods. The Search for Meaning. New York: John Wiley and Sons.

WHO (World Health Organization), 1997. Unsafe Abortion. Global and Regional Estimates of Incidence of and Mortality Due to Unsafe Abortion with a Listing of Available Country Data. Division of Reproductive Health (Technical Report). 3rd Ed. Geneva: WHO.

WHO (World Health Organization), 1998. Emergency Contraception: A Guide for Service Delivery. Geneva: WHO.

Submitted on April 4, 2003

Approved on July 31, 2003 